\title{
O CNJ E OS DISCURSOS DO DIREITO E DESENVOLVIMENTO
}

\author{
Ivan Candido da Silva de Franco e Luciana Gross Cunha
}

\section{RESUMO}

ESTE ARTIGO PRETENDE TESTAR A APLICABILIDADE DA LITERATURA NO CAMPO DO DIREITO E DESENVOLVIMENTO EM UMA FACETA ESPECÍFICA DA REFORMA DO JUDICIÁRIO: O CONTROLE DISCIPLINAR EXERCIDO PELO CONSELHO NACIONAL DE JUSTIÇA (CNJ). Primeiramente, exploramos a literatura dominanTE DE REFORMAS INSTITUCIONAIS, DE MODO A FICAREM CLAROS SEUS PRINCIPAIS PRESSUPOSTOS TEÓRICOS, O QUE É SEGUIDO PELA EXPOSIC̣ÃO DE CORRENTES CRÍTICAS A ESSAS ABORDAGENS. SÃO DESCRITAS, EM SEGUIDA, AS PRINCIPAIS ALTERAÇÕES PROMOVIDAS PELO CNJ, BEM COMO SÃO DEMONSTRADOS ALGUNS DE SEUS EFEITOS, QUE JÁ PODEM SER SENTIDOS. ESSE CAMINHO PERMITE INICIAR A RESPOSTA À PERGUNTA DO ARTIGO SOBRE A PERTINENNCIA DOS MARCOS TEÓRICOS DOMINANTES À PROBLEMÁTICA DA FUNÇÃO DISCIPLINAR DO CONSELHO, AVALIANDO, COM ISSO, A ADERÊNCIA DESSAS TEORIAS À REALIDADE BRASILEIRA. PARA TANTO, FOI FEITO O MAPEAMENTO DE ARGUMENTOS FREQUENTEMENTE UTILIZADOS NAS ABORDAGENS SOBRE REFORMAS INSTITUCIONAIS NO CAMPO ESTUDADO COM O FIM DE VERIFICAR SUA RESPONSIVIDADE AOS PRINCIPAIS DEBATES SURGIDOS À ÉPOCA DA CRIAÇÃO DO CNJ APÓS CONSTATAR QUE ESSAS CONSTRUÇÕES TEÓRICAS NÃO SÃO SUFICIENTES, SUGERIMOS FORMAS DE ALIAR ABORDAGENS DE DIREITO E DESENVOLVIMENTO A SITUAÇÕES CONCRETAS, CONSIDERANDO AS RELEVANTES VARIAÇÕES LOCAIS, MUITAS VEZES RELEGADAS PELAS TEORIAS DOMINANTES.

\section{PALAVRAS-CHAVE}

DIREITO E DESENVOLVIMENTO; TEORIAS DOMINANTES; REFORMAS institucionais; Conselho Nacional de Justiça (CNJ).

\section{ABSTRACT}

THIS ARTICLE AIMS TO TEST THE APPLICABILITY OF THE PREVAILING THEORIES IN THE LAW AND DEVELOPMENT FIELD IN A SPECIFIC ASPECT OF THE JUDICIAL REFORM: THE DISCIPLINARY CONTROL IN THE National Justice COUNCIL (CNJ). First OF ALL, WE EXPLORE THE DOMINANT LITERATURE OF INSTITUTIONAL REFORMS, TO CLARIFY ITS MAIN THEORETICAL ASSUMPTIONS, WHICH IS FOLLOWED BY THE EXPOSURE OF CRITICAL APPROACHES ABOUT THEM. THE MAIN CHANGES INTRODUCED BY THE CNJ ARE THEN DESCRIBED, AND SOME OF THEIR EFFECTS ARE SHOWN, EFFECTS THAT CAN ALREADY BE FELT. THIS PATH ALLOWS US TO START THE ANSWER TO THE MAIN QUESTION OF THE ARTICLE, WHICH IS THE RELEVANCE OF THE DOMINANT THEORETICAL FRAMEWORKS TO THE PROBLEM OF THE DISCIPLINARY FUNCTION OF THE COUNCIL, ASSESSING, THEREBY, THE ADHESION OF THESE THEORIES TO THE BRAZILIAN REALITY. THE WORK WAS DONE BY DESCRIBING COMMONLY USED ARGUMENTS ON INSTITUTIONAL REFORMS' APPROACHES IN THE FIELD IN ORDER TO VERIFY THEIR RESPONSIVENESS TO THE MAIN DEBATES THAT AROSE AT THE TIME OF THE CREATION OF THE CNJ. HAVING ESTABLISHED THAT THESE THEORETICAL FRAMEWORKS ARE NOT SUFFICIENT, WE SUGGEST WAYS TO COMBINE APPROACHES OF LAW AND DEVELOPMENT TO CONCRETE SITUATIONS, CONSIDERING THE RELEVANT LOCAL VARIATIONS OFTEN RELEGATED BY THE DOMINANT THEORIES.

\section{KEYWORDS}

LAW AND DEVELOPMENT; PREVAILING THEORIES; INSTITUTIONAL REFORMS; NATIONAL JUSTICE COUNCIL (CNJ). 
Os senhores acham que o Estado de Direito no Brasil está enfraquecido? (...) Nós temos, seguramente, a mais sólida democracia da América Latina. Me causa estranheza pedir o fortalecimento das instituições democráticas, mas, enfim, eu vou ler o documento. (...) Os senhores não representam o CNJ. Os senhores não representam a nação. São representantes de classe. Mas eu não vim para debater com os senhores. (...) O CNJ não necessita de apoio. (...) Os seus atos estão previstos na Constituição e nas leis. ${ }^{1}$

JOAQUim BARBOSA, Ministro-Presidente do STF e do CNJ no biênio 2012-2014, em reunião com Associações da Magistratura.

\section{INTRODUÇÃO:}

REFORMA DO JUDICIÁRIO E O MODELO DE DESENVOLVIMENTO BRASILEIRO

A Emenda Constitucional n. 45, aprovada em dezembro de 2004 (EC45/2004) foi responsável por transformações importantes no Judiciário brasileiro, ficando conhecida como Reforma do Judiciário. Sua tramitação no Congresso Nacional foi longa, tendo sido iniciada em 1992 (com a PEC 96) e concluída mais de uma década depois. Durante esse período, o projeto foi alterado diversas vezes, indicando a existência de interesses distintos que orbitaram a aprovação dessa Emenda à Constituição Federal. O resultado desse processo, entre outros, foi a introdução da possibilidade de edição de súmulas vinculantes pelo Supremo Tribunal Federal e o critério da repercussão geral. O controle do Poder Judiciário é fruto do mesmo processo, que introduziu o Conselho Nacional de Justiça (CNJ) em nosso ordenamento constitucional.

Os interesses que circundaram essas profundas alterações não eram restritos a determinadas associações de classe da magistratura, que abertamente defendiam suas posições corporativas. Literatura recente aponta o Supremo Tribunal Federal como diretamente interessado no desenho institucional do Judiciário, notadamente em seu novo órgão: o CNJ. O Conselho criado exerceria papel estratégico no autogoverno do Poder, pois teria papel central em seu gerenciamento. Isso se torna ainda mais relevante porque essa função vinha sendo exercida pelo próprio STF (CARVALHO; LEITÃO, 2013). O CNJ é um órgão administrativo de cúpula do Poder Judiciário. Não detém qualquer função jurisdicional, mas exerce função administrativa centralizada. Seu controle se exerce sobre a atuação administrativa e financeira do Poder Judiciário, além da fiscalização sobre os deveres funcionais dos seus membros (art. 103-B, $\S 4^{\circ} \mathrm{da} \mathrm{CF}$ ). O controle sobre os atos do CNJ, por sua vez, é exercido originariamente pelo Supremo Tribunal Federal (art. 102, I, "r" da CF).

Após um questionamento judicial sobre sua constitucionalidade, logo após sua criação, ${ }^{2}$ o órgão acabou se firmando e hoje faz parte da realidade brasileira, organizando a atuação dos tribunais e de seus integrantes e trazendo à discussão as condutas desses na administração da Justiça. 
A afirmação do ministro do STF Joaquim Barbosa, em 2013, de que o CNJ já está consolidado e que, por isso, não necessita de apoio, na paráfrase utilizada por ele e indicada no início desse artigo, podem ser reveladoras de outros pontos. As menções ao Estado de Direito e às instituições democráticas não são casuais. Elas podem ser entendidas como reflexo de um discurso muito falado e pouco refletido sobre Rule of Law, o qual teve influência na Reforma do Judiciário de 2004 e, por consequência, na criação do CNJ. Esse discurso é oriundo da visão teórica majoritária sobre reformas institucionais, que enxerga uma relação direta entre eficiência do Judiciário e desenvolvimento econômico, e tem uma agenda racionalizadora e centralizadora (CUNHA; ALMEIDA, 2012). Resta saber se esse entendimento teórico é pertinente para a compreensão da realidade brasileira.

Este artigo pretende testar a aplicabilidade dos discursos acadêmicos no campo do Direito e Desenvolvimento em uma faceta específica da Reforma do Judiciário: o controle disciplinar no Conselho Nacional de Justiça. De que forma o Direito e Desenvolvimento e os discursos que esse campo do direito organiza respondem à função sancionatória exercida pelo CNJ? Verificar a pertinência do Direito e Desenvolvimento aos debates concretos que circundaram a aprovação da EC 45/2004, no que diz respeito ao $\mathrm{CNJ}$, é uma forma de demonstrar sua aderência ou não à realidade estudada. Nosso estudo, restrito à análise de um aspecto específico da Reforma do Judiciário, pretende ser um ponto de partida para a reflexão sobre a influência dos discursos acadêmicos que tratam de reformas institucionais, sobre a criação e formação do CNJ.

Primeiramente, iremos mapear as principais abordagens teóricas de Direito e Desenvolvimento, para, em seguida, focarmos na literatura sobre as reformas institucionais e a forma pela qual ela é capaz de nos fornecer subsídios para o entendimento da criação e do funcionamento do CNJ, enquanto órgão capaz de exercer controle disciplinar. Posteriormente, descreveremos as principais características do CNJ, com foco em seus aspectos de controle disciplinar. Após, testaremos os marcos teóricos dominantes à situação concreta do Conselho, de modo a examinar se eles são suficientes para compreender a realidade brasileira. Após constatar que essas abordagens não são suficientes, teceremos breves sugestões sobre como aliar abordagens teóricas de Direito e Desenvolvimento a situações concretas, considerando as relevantes variações locais, por vezes relegadas pelas teorias dominantes.

\section{i Abordagens teóricas de Direito \\ E DesenVOLVIMENTO E A REFORMA INSTITUCIONAL}

\section{I As abordagens de Direito e Desenvolvimento}

O campo teórico que pode ser identificado por alguns como Direito e Desenvolvimento 
não possui linhas bem delimitadas - tão pouco é reconhecido de forma inconteste pela literatura. ${ }^{3}$ Este artigo, no entanto, não irá tratar dessa polêmica, mas partirá da premissa de que algum modelo de desenvolvimento - ou uma junção de elementos de diferentes modelos - inspirou as reformas empreendidas pela Emenda Constitucional 45/2004, conhecida como Reforma do Judiciário. O objetivo deste artigo, como dito, será o de verificar a pertinência dos marcos teóricos dominantes em matéria de reformas institucionais para refletir sobre a melhor forma de se pensar a realidade brasileira. Primeiramente, apresentaremos um breve mapeamento das grandes abordagens da literatura específica.

Para essa descrição dos movimentos da literatura sobre Direito e Desenvolvimento será utilizada a tipologia da autora Mariana Mota Prado (2010). Para ela, há dois grandes grupos nos quais os autores estudados se inserem: Law in Development, segundo o qual o direito pode desempenhar um papel instrumental na busca por determinados objetivos; e Law as Development, que entende as reformas legais com o objetivo de estabelecimento do Rule of Law nos países como um fim em si mesmas.

Uma primeira Escola de Pensamento do Law in Development entendia que o papel do Estado seria central para a realização dos objetivos traçados. Nesses casos, o Estado interventor era defendido, e o direito poderia ser utilizado como um meio para sustentar essas atividades estatais. Pode-se denominar essa Escola de law in the developmental state (PRADO, 2010).

Uma segunda Escola, historicamente posterior à descrita, embora sob semelhante concepção acerca do papel do direito, ficou conhecida por seu pensamento orientado para o mercado. Essa Escola, que pode ser chamada de law in the neoliberal state (PRADO, 2010), defendia a intervenção mínima do Estado, de modo a assegurar um mais livre mercado.

No campo do Law as Development, vale recordar, há uma ideia segundo a qual o direito e, consequentemente, o modelo legal por ele gerado são um fim em si mesmos. O estabelecimento do Rule of Law pode ser considerado o objetivo de desenvolvimento.

Grande expoente desse campo foi Amartya Sen, que concebe o desenvolvimento de uma forma inovadora. O autor se contrapõe às teorias do desenvolvimento que atentam ao desenvolvimento econômico e relegam ao segundo plano outras variáveis relevantes que deveriam compor um conceito mais adequado e completo de desenvolvimento. Sua linha teórica é a do Desenvolvimento como liberdade (SEN, 2000a).

A grande dicotomia levantada pelo autor é a liberdade, de um lado, e a privação, de outro. A sociedade orientada para o mercado pode gerar exclusão (ou privação) para determinados setores. Sua teoria não nega a lógica de mercado, mas procura conciliar sua existência com a expansão das liberdades das pessoas, sendo essa a forma de atingir o desenvolvimento. As liberdades, que são de várias ordens (econômica, social, política) e interligadas, são apresentadas como os mais relevantes fins do desenvolvimento ao mesmo tempo em que são os mais relevantes meios para 
ele (SEN, 2000a).

Outra forma de pensar, que não se opõe à exposta anteriormente, foi difundida com a chamada institutional perspective on development (PRADO, 2010). Essa perspectiva teórica entende que pessoas nas diferentes sociedades respondem a incentivos, os quais são criados pelas instituições. A melhora de instituições que não funcionam, ou que são de alguma forma disfuncionais, levaria ao desenvolvimento. Desse movimento surge a máxima sustentada por relevante parcela da literatura - e encampada em muitas das ações de órgãos multilaterais desde então -, segundo a qual institutions matter.

Um dos autores reconhecidos como fundador dessa discussão é Douglas North. Segundo ele, as instituições ${ }^{4}$ são responsáveis por guiar o comportamento humano. Sua existência reduz as incertezas, pois elas operam de forma contínua em qualquer sociedade. Não são necessariamente eficientes, mas são estáveis, e essa característica explica sua influência nas interações humanas. Essas regras do jogo são tanto formais quanto informais, o que pode ser extraído de qualquer sociedade conhecida que opera segundo ambos os tipos de regras de forma conjunta (NORTH, 1990).

A mudança institucional que leva a um conjunto de instituições funcionais não é simples. Cada sociedade tem sua história, e escolhas feitas no passado influenciam as possibilidades futuras. Instituições, mesmo as disfuncionais, têm a capacidade de self-reinforcing, o que dificulta um processo de mudança. North (1990) denomina esse fenômeno de path dependence, que é o contínuo peso exercido pelas escolhas passadas nas futuras. Explicando,

at every step along the way there were choices - political and economic - that provided real alternatives. Path dependence is a way to narrow conceptually the choice set and link decision making through time. It is not a story of inevitability in which the past neatly predicts the future (NORTH, 1990, p. 98 e 99).

\section{I.2 Reformas institucionais: O RULE OF LAW E SUAS CRÍTICAS}

A abordagem institucional dominante no Direito e Desenvolvimento, quando levada à prática, frequentemente define reformas no Poder Judiciário como ações primordiais para o desenvolvimento econômico de uma dada sociedade. Essas iniciativas buscam o estabelecimento do Rule of Law nas mais diferentes realidades.

O conceito de Rule of Law não é uno. Nem mesmo nas agências internacionais, que o adotam e propagandeiam a sua adoção pelos mais diferentes países, há uma delimitação mais concreta do significado da expressão. Isso a aproxima de uma colcha de retalhos ${ }^{5}$ (CUNHA, 2011), utilizada para agasalhar os mais diferentes parâmetros.

Tipicamente, podemos dizer que esse receituário prega o estabelecimento de um sistema legal nos moldes daqueles existentes em países ricos, sendo garantidos, especialmente, os direitos de propriedade e o enforcement de contratos. A busca por eficiência e segurança jurídica está por trás desse pensamento, principalmente em sua relação 
com o Judiciário.

O já mencionado Douglas North é um autor identificado com a agenda do Rule of Law. Para ele, as instituições em uma dada sociedade são centrais para a compreensão dos processos internos a ela, notadamente sua performance econômica. A teoria construída pelo autor procura demonstrar que as mudanças institucionais - substituindo arranjos disfuncionais por funcionais - são o motor para o desenvolvimento econômico. Para explicar as diferenças notáveis entre os países ricos e pobres, o autor menciona a existência do path dependence e de custos de transação e transformação, o que pode dificultar esse virtuoso processo de mudança (NORTH, 1990).

Amartya Sen poderia ser qualificado como um autor alinhado à agenda do Rule of Law, nos termos descritos neste artigo. Apesar de sua noção de desenvolvimento como liberdade poder ser tida como mais eclética, por não contemplar apenas o crescimento econômico mas uma forma de desenvolvimento mais ampla, muitas de suas ideias se coadunam com o pensamento dominante acerca da relação entre reformas legais e judiciais e desenvolvimento econômico.

As reformas empreendidas não poderiam levar em conta apenas uma variável, seja qual for - econômica, política, social. As reformas devem ser guiadas por uma ideia de todo, e não segundo uma concepção de reformas localizadas e isoladas (SEN, 2000b). Dentro dessa noção abrangente de desenvolvimento, as reformas legais seriam uma parte essencial do todo. Nas palavras do autor, "development has a strong association of meanings that makes a basic level of legality and judicial attainment a constitutive part of it” (SEN, 2000b, p. 9).

Esse pensamento, dominante, reforça a crença segundo a qual a performance econômica é influenciada por elementos não econômicos. O autor resgata as origens do capitalismo ocidental para afirmar que arranjos legais propiciaram o desenvolvimento econômico de então. São as relações entre as mais diferentes instituições as responsáveis por um desenvolvimento satisfatório (SEN, 2000b).

Apesar de diferenças que particularizam seus autores, podemos identificar nessa forma de pensamento a ideia de modernização dos países subdesenvolvidos. Esse processo é muitas vezes identificado com reformas legais, que ajustariam esses países ao caminho do desenvolvimento. O transplante de modelos funcionais de países ricos foi e é uma alternativa existente e relevante. Por todos, podemos mencionar um autor norte-americano que entende que esse processo é desejável. Nas suas palavras: "one approach might be to establish a law reform commission to rationalize, unify and modernize national laws, borrowing whenever possible from established foreign models" (POSNER, 1998 , p. 6, grifo nosso).

Essa construção demonstra uma noção clara de que o caminho para o desenvolvimento institucional de um país está na mimetização dos passos dados pelos países hoje desenvolvidos. Por mais que o próprio autor reconheça a necessidade de participação de atores locais para a realização das reformas, o fato da menção à necessidade de adaptar 
normas estrangeiras demonstra muito do que se pensa sobre desenvolvimento próprio.

Ressalvas como as realizadas por um autor típico do pensamento dominante do Rule of Law são fruto da influência de uma literatura alternativa que vem ganhando corpo no campo do Direito e Desenvolvimento. De forma geral, esses autores, por meios distintos, vêm defendendo que a abordagem predominante pode conter problemas. A proteção de direitos de propriedade e o enforcement dos contratos, realizados em grande medida pelo Poder Judiciário como condicionantes necessárias para o desenvolvimento econômico, podem não ser sempre verdadeiras.

Critica-se, em suma, a predeterminação do caminho, como se houvesse uma fórmula a ser seguida para o desenvolvimento. Essa abordagem prevalecente e criticada por novos estudiosos, também chamada de endownment perspective, é assim explicada (MILHAULPT; PISTOR, 2008, p. 17-18):

(...) it treats a legal system as if it were like a highway or a dam - a fixed investment that must be built before economic development can take off but than once in place determines the path of development without itself being subject to change.

A ideia de mero transplante de sistema legal é colocada em xeque. Outros fatores são levados em consideração. Mais do que isso, outros modelos de desenvolvimento começam a apresentar resultados pelo mundo, sendo exemplares os casos dos países asiáticos, notadamente o da China (OHNESORGE, 2006). Como explicar o seu desenvolvimento econômico praticamente à margem de um sistema legal-ocidental ou, em outros termos, do Rule of Law?

Esses questionamentos e críticas têm ganhado força. A abordagem institucional já tida como grande solução para o problema do desenvolvimento dos países pobres está longe de ser consensual. Ou seja, a "universalização de um conjunto de instituições 'corretas' (getting the institutions right) (...) desenhadas como uma espécie de dispositivos pré-moldados, aptos a serem aplicados nos mais diversos modelos de economia e sociedade (reformas one size fits all)" não levou aos resultados esperados pelos seus principais formuladores de políticas (SCHAPIRO; TRUBEK, 2012, p. 40). Isso aumenta a desconfiança sobre a funcionalidade de tais reformas.

Há quem questione estruturalmente a necessidade de determinadas reformas. Thomas Carothers (2006) afirma que a escolha por reformas no Poder Judiciário não é necessariamente baseada em motivações mais acuradas; pode ser atribuída à própria experiência de vida dos reformadores - em geral, advogados, que enxergam na ineficiência do Judiciário um grande problema para o desenvolvimento de um país.

$\mathrm{O}$ autor sugere que a resposta pode estar em estruturas mais relevantes para o desenvolvimento de um país. Sugere, por exemplo, que o Judiciário exerce um papel mais tardio, sendo que maior importância pode ser atribuída à atividade legislativa. 
"Yet for the last ten to fifteen years, rule-of-law programs have given dominant attention to judiciaries, without much examination of whether such a focus is really the right one" (CAROTHERS, 2006, p. 20). Por essas razões, são questionadas práticas como institutional checklists, que pressupõem mudanças “corretas” para os países em geral.

Apesar das críticas, as reformas institucionais empreendidas em países subdesenvolvidos ainda são embasadas pelo corpo teórico dominante. A crença de que mudanças institucionais levam ao desenvolvimento econômico inspira países e pauta programas de agências multilaterais, notadamente o Banco Mundial. Resta saber se essas noções teóricas auxiliam a resolução de problemas concretos enfrentados por países que se engajam em reformas institucionais.

\section{O CONTROLE DisciplinAR NO CNJ}

\section{I ORIGENS E PRINCIPAIS CARACTERÍSTICAS}

O Brasil passou recentemente pela Reforma do Judiciário. Essa grande mudança constitucional, realizada há menos de dez anos, traz diferentes interpretações sobre seus resultados. Na literatura sobre Direito e Desenvolvimento, podemos destacar recente publicação que se debruçou em entender os sentidos dessas mudanças:

Já a proposta aprovada em 2004, criou um conjunto de instrumentos judiciais que centralizaram a tomada de decisões no Judiciário, ao mesmo tempo que exigiu que ele fosse responsivo e transparente na prestação de um serviço de qualidade em termos de custos, tempo e capacidade técnica, produzindo decisões racionais e coerentes. Essa agenda "centralizadora e racionalizadora" da atividade judicial foi resultado de discursos que indicavam os impactos negativos do Poder Judiciário sobre a atividade econômica, principalmente no que diz respeito à morosidade no processamento dos casos e à falta de coordenação e padronização administrativa e jurisprudencial do Poder Judiciário

(CUNHA; ALMEIDA, 2012, p. 365)

Segundo os autores, portanto, a Reforma do Judiciário como um todo, ao contrário do que se previa em seu projeto original do início dos anos 1990, privilegiou agendas típicas do Rule of Law. O Conselho Nacional de Justiça, instrumento de controle externo do Poder Judiciário, também está inserido nessas reformas. Mas podemos nos questionar: o CNJ cumpre funções semelhantes à Reforma entendida como um todo ou ele guarda particularidades relevantes? O receituário dominante consegue dar respostas aos principais questionamentos existentes quando da criação do órgão?

A ideia de um controle externo ao Poder Judiciário não é genuinamente nacio- 
nal. Há experiências prévias, relevantes e que provavelmente inspiraram a nossa na Europa do Sul (Itália, Portugal e Espanha). Em cada um dos países em que foi criado, o Conselho procurou combater as deficiências dos Judiciários locais, com maior ou menor sucesso (CARVALHO, 2006).

No Brasil, o CNJ nasce como um órgão administrativo de cúpula com vistas a controlar um Poder que, na famosa frase do ex-presidente Lula da Silva, era uma “caixa-preta”. Houve, como poderia se esperar, resistência de setores da magistratura, em especial de segundo grau e de tribunais superiores, pois “(...) apesar de existir uma retórica democrática nas diversas instituições judiciárias brasileiras, é muito baixo o apoio dos juízes a uma instituição de controle administrativo da justiça composta por membros estranhos à magistratura" (CARVALHO, 2006, p. 107).

A existência de uma retórica democrática é destacável. Isso porque essa é uma constante que pode ser observada ainda hoje. No caso envolvendo as Associações de Magistrados e o atual Presidente do STF e do CNJ, é notável a presença de um discurso democrático, de ambos os lados. No plano do discurso, um mesmo ideal é levantado por lados opostos em questões concretas. Veremos que, no plano dos trabalhos teóricos, discursos similares são invocados para justificar políticas discrepantes.

Não só a atividade que seria exercida por um Conselho de Justiça causava resistência. Talvez em grau ainda mais elevado, a própria composição do órgão era objeto de ferrenha oposição. É notável, na tabela seguinte, a menor simpatia pelo CNJ composto por membros externos do Poder Judiciário, por parte de juízes de carreira.

\section{TABEla 1 - OPINIÃo DE MAgISTRAdOS SOBRE PROPOSTAS DE REFORMA do JUdiciário (EM \%)}

PROPOSTAS FAVORÁVEL IRRELEVANTE CONTRA N.S./N.R.

\begin{tabular}{rllll}
\hline CRIAR O CNJ & 39,0 & 21,0 & 25,5 & 14,5 \\
\hline CNJ: COMPOSTO POR MEMBROS DO JUDICIÁRIO & 48,5 & 19,0 & 16,5 & 16,0 \\
\hline CNJ: INCLUINDO MEMBROS EXTERNOS AO JUDICIÁRIO & 20,0 & 14,0 & 47,0 & 19,0 \\
\hline
\end{tabular}

Fonte: SADEK, 2001b. Tabela fruto de pesquisa realizada no ano 2000 com 738 juízes, de primeiro e segundo graus, das Justiças Estadual, Federal e do Trabalho, de 12 unidades federativas.

A composição causava resistência por alguma razão. Entendemos que a atividade de controle disciplinar exercia influência bastante grande nesse aspecto. Isso porque dos três grandes pontos questionados por esses setores que se opunham à criação do CNJ, dois tinham relação direta com a matéria correcional, e o outro, indireta. Os três principais pontos da discórdia (CARVALHO, 2006) relativa à presença de conselheiros não juízes seriam: 
1) Falta de conhecimento específico sobre o funcionamento da justiça;

2) Existência de um forte controle interno exercido pelos tribunais;

3) Flagrante perigo à independência judicial. ${ }^{6}$

Esses pontos serão explorados à luz dos marcos teóricos traçados até então. Por ora, vale lembrar que saiu vencedora a tese sustentada pelo Governo Federal à época, de um Conselho de Justiça eclético, com membros externos à magistratura. A EC 45/2004 criou o já referido artigo 103-B de nossa Constituição, para a função de controle da atuação administrativa e financeira do Poder Judiciário e do cumprimento dos deveres funcionais dos juízes. Para tanto, o desenho institucional ficou da seguinte forma: nove conselheiros juízes, oriundos da magistratura, e seis conselheiros não juízes, oriundos da advocacia, do Ministério Público (MP) e da sociedade civil. Essa classificação se refere à função exercida pela pessoa quando de sua nomeação. Fazemos essa ressalva porque é possível que algum membro escolhido da segunda instância tenha origem no quinto constitucional ou, ainda, tenha outra origem, quando escolhido de tribunais superiores.

Apesar da composição com grau de exterioridade de 40\% (CARVALHO, 2006), podemos observar uma notável proeminência dos conselheiros juízes. Não à toa, os dois cargos mais relevantes são ocupados por membros de Tribunais Superiores: a Presidência, pelo Ministro-Presidente do STF, e a Corregedoria Nacional de Justiça, pelo representante do STJ. Isso indica que, apesar de termos uma participação relevante dos conselheiros não juízes, as funções primordiais do CNJ estão nas mãos de membros da própria magistratura.

O Conselho Nacional de Justiça realiza suas funções com essa composição. Mesmo em meio a tantos conflitos entre Poderes, a função correcional chama a atenção. $O$ $\mathrm{CNJ}$ tem, realmente, exercido seu papel de controle disciplinar da magistratura. E o faz de forma a iluminar com publicidade a até então "caixa-preta": há intensa exposição dos membros do Poder Judiciário, com a divulgação completa do nome dos magistrados frente à suspeita de cometimento de infração disciplinar, bem como julgamentos sendo transmitidos ao vivo por meio do portal eletrônico do Conselho. A punição aos membros desse Poder se dá aos olhos de qualquer cidadão. Esse quadro é novo para um Poder que, até pouco tempo, era controlado ordinariamente por seus pares - e que, mesmo após a promulgação da Constituição de 1988, não conhecia uma fiscalização substancial exercida sobre desembargadores (TOMIO; ROBL FILHO, 2013).

Os mecanismos de transparência ativa do Conselho Nacional de Justiça têm sido aprimorados nos últimos anos. A divulgação de salários de magistrados e a organização dos processos disciplinares envolvendo magistrados da maior parte dos Tribunais 
do país são alguns exemplos. Precisaríamos saber se os cidadãos se sentem agasalhados pelo CNJ, ou seja, se ele é poroso à participação e envolvimento da sociedade civil em suas mais distintas funções.

A atividade disciplinar do CNJ tem, todavia, seus limites. Há diagnósticos de que muitos de seus resultados recentes tenham se dado pela liderança pessoal da exCorregedora Nacional de Justiça Eliana Calmon ou, ainda, que mesmo a mais severa sanção aplicada a um juiz vitalício seja a tímida aposentadoria compulsória (LASSANCE, SÁ E SILVA, 2013). Havia previsão, na redação final da PEC 96/1992, de punição mais rigorosa, isto é, a perda do cargo de magistrado aplicada pelo CNJ por meio do voto de três quintos de seus membros. Sua não aprovação, para alguns, resulta em perda de accountability judicial (TOMIO; ROBL FILHO, 2013). Mesmo assim, é difícil negar os avanços em termos de controle, que são fruto da Reforma.

Descrevemos, brevemente, alguns resultados da criação do Conselho Nacional de Justiça. Neste momento, passaremos à análise da contribuição da literatura sobre Direito e Desenvolvimento para esse quadro. Buscaremos entender em que medida as concepções dominantes puderam contribuir para a forma como se organizou o Conselho, de forma a construir um diagnóstico crítico sobre sua pertinência à realidade brasileira.

\subsection{COMO OS MARCOS TEÓRICOS DOMINANTES RESPONDERAM ÀS DEMANDAS CONCRETAS?}

As noções teóricas vistas até agora conseguem responder às principais discórdias localizadas na experiência brasileira? O objetivo, neste momento, é o de verificar se a literatura sobre reformas institucionais, dominante no campo do Direito e Desenvolvimento, consegue responder minimamente aos problemas locais, às situações concretas ocorridas em um país também alimentado pelo receituário do Rule of Law. Esse exercício poderá verificar, em um caso concreto e sob determinadas variáveis, o alcance de marcos teóricos influentes, a fim de avaliar se eles se aplicam à realidade específica de um país em desenvolvimento ou se, ao contrário, são identificados a uma noção one size fits all menos responsiva às peculiaridades locais.

A escolha metodológica das variáveis locais recaiu sobre os três principais pontos de discórdia levantados por setores da magistratura, relativos à existência de conselheiros não juízes no Conselho Nacional de Justiça (CARVALHO, 2006). Os problemas apontados foram: falta de conhecimento específico sobre o funcionamento da justiça; existência de forte controle interno exercido pelos tribunais; flagrante perigo à independência judicial. A escolha se deve à existência e relevância desses questionamentos na experiência prática brasileira.

Analisaremos cada um dos três pontos para verificar a pertinência das noções teóricas aplicadas aos casos concretos.

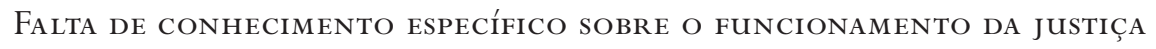


Identificamos esse argumento como uma alegação tipicamente corporativista. É evidente que os membros de um determinado Poder da República têm um conhecimento considerável das mais específicas nuances do seu funcionamento. Porém, utilizar-se dessa condição para barrar a participação de membros externos ao Poder Judiciário é um argumento corporativo. Ainda mais porque os seis conselheiros não juízes são membros da advocacia, do MP e da sociedade civil com notável saber jurídico, o que indica conhecimento de nosso sistema de justiça (CARVALHO, 2006).

A produção teórica na literatura estudada não identifica esse tipo de questão. A reforma do Poder Judiciário, em uma chave que leva em conta a maior eficiência da prestação jurisdicional, não considera a questão corporativa. Longe de ser uma variável marginal, a postura de determinados setores da magistratura brasileira foi central nas discussões em torno do Projeto de Emenda Constitucional (e ainda é). A oposição à consolidação do Conselho Nacional de Justiça como órgão administrativo de cúpula do Poder Judiciário é constantemente posta em xeque, principalmente pelas associações de classe. ${ }^{7}$ A existência de um Poder fechado, com plano de carreira rígido e ligado a uma noção de hierarquia, não é característica do Brasil, mas de boa parte dos países da América Latina (THOME, 2000).

As associações de classe da magistratura se manifestaram durante a tramitação da PEC 96/1992, demonstrando suas principais insatisfações (SADEK, 2001a). Também tiveram influência após a aprovação da Emenda Constitucional 45/2004, quando, no primeiro ano de funcionamento do CNJ, propuseram uma Ação Direta de Inconstitucionalidade (ADI 3.367/2005) questionando a existência e a composição do órgão. Por maioria de votos, ela foi declarada improcedente. Porém, a iniciativa demonstra a relevância desse aspecto na realidade brasileira, algo que não é discutido profundamente pela literatura dominante de Rule of Law.

\section{EXISTÊNCIA DE UM FORTE CONTROLE INTERNO EXERCIDO PELOS TRIBUNAIS}

Trata-se, nesse caso, de uma questão federativa. De um lado, uma Reforma que propunha a centralização de diversas atribuições do Poder Judiciário - de que é grande exemplo a súmula vinculante e, no que interessa diretamente ao objeto do estudo, o controle disciplinar pelo Conselho Nacional de Justiça. De outro, setores da magistratura que entendiam que já havia um controle adequado por parte dos Tribunais, exercido de forma local, e que não haveria necessidade de um órgão central para exercer essa mesma função.

Novamente, uma associação de classe propôs uma Ação Direta de Inconstitucionalidade (ADI 4.638/2012) questionando dispositivos da Resolução 135/2011 do CNJ que unifica a matéria disciplinar aplicável aos magistrados. Questionava-se, no fundo, a competência do CNJ em normatizar de forma nacional o processo aplicável aos magistrados. Apesar de o questionamento formal ter sido rechaçado no STF, o julgamento do dispositivo que de forma mais evidente expunha essa 
questão federativa foi decidido pela maioria mínima de votos: cinco ministros foram favoráveis à competência concorrente do CNJ, e quatro ministros, de forma diversa, entenderam ser a competência subsidiária, podendo ser exercida somente após a apreciação local.

A questão federativa, a constante tensão entre poder central e poder local não é algo discutido pela literatura dominante. O movimento de centralização e descentralização administrativa não é tocado pelas noções teóricas em comento. Na história brasileira, esse caminho importa muito e, nos termos de North (1990), é fonte de um path dependence que gera cisões até hoje. Uma questão dessa relevância pode ser extraída da literatura de forma colateral e indireta.

Além disso, devemos mencionar a disparidade de opiniões dentro da magistratura, que possivelmente reflete uma situação externa e bastante peculiar à realidade brasileira. A maior oposição às reformas foi localizada no topo da magistratura, notadamente nos membros de Tribunais. Isso pode refletir a ineficiência do controle existente até então sobre os desembargadores (CARVALHO, 2006).

\section{Flagrante PERIGO À INDEPENDÊNCIA JUDICIAL}

O controle do Judiciário pode esbarrar na menor independência dele. Em outras palavras, a competência disciplinar poderia adentrar na atividade jurisdicional exercida pelos magistrados e, em decorrência disso, afetar a independência em seus julgamentos, vez que o juiz deve ter compromisso com sua livre convicção e não cogitar da possibilidade de ser punido por conta de posturas nos autos de processos. O temor da punição poderia afetar o melhor desempenho da função.

O tema é discutido desde os primeiros anos do debate legislativo (SADEK, 2001a), principalmente por conta da desconfiança do controle externo sobre a magistratura. A literatura identificada com o Rule of Law, nesse ponto, traz grandes contribuições. Não é incomum o discurso da garantia da independência do Poder Judiciário, o que traria ganhos à eficiência da prestação jurisdicional e, ainda, maior desenvolvimento econômico. Muitas das políticas de órgãos multilaterais, que bebem dessa mesma fonte teórica, defendem a independência judicial como um valor central para o desenvolvimento dos países em que o Poder atua. Nesse sentido, é inegável a contribuição desses marcos teóricos dominantes à reflexão sobre um modelo de reforma judicial, respondendo às questões locais.

A solução institucional encontrada para equilibrar a existência de um Conselho independente com mecanismos de controle, de modo a tranquilizar setores que temiam uma atuação irrefreável do CNJ, foi o controle judicial. Conforme já mencionado, o Supremo Tribunal Federal é o responsável por essa missão constitucional, sendo o competente originário em processos que envolvam o Conselho. Resta saber se essa solução tem funcionado a contento. 


\subsection{ESTABELECENDO DIFERENCIAÇÕES TEÓRICAS}

Não há uma necessária confluência de sentidos em reformas propostas por global actors e domestic actors (THOME, 2000). Os primeiros são identificados com as agências multilaterais, notadamente o Banco Mundial, com concepções de Rule of Law descritas anteriormente; os segundos constituem um grupo mais difuso, sem uma identificação teórica tão clara.

Por mais que as agências multilaterais venham - ao menos no plano do discurso adequando-se às especificidades locais e por mais que muitos atores locais tenham ligação com posturas globais, as diferenças entre essas abordagens devem ser destacadas. Partem de premissas distintas e podem apontar para soluções diversas. Ou, como visto, podem simplesmente não tocar em situações que constituam relevantes problemáticas locais, centrais a uma reforma do Judiciário aderente à realidade. Como salienta um autor crítico à importação de modelos:

None (...) is to deny that judiciary and legal processes in Latin America do not need substantial improvement. Their inadequacies and problems have been well-documented. But there are clear risks in using models from the North to fix the legal "insufficiencies" without due regard to the particular needs and contexts of the Southern "receiving" societies (THOME, 2000, p. 701).

Além de muitas vezes não responder adequadamente às particularidades locais, essa literatura dominante insiste na relação causal entre Reforma do Judiciário e crescimento econômico. Um eficiente órgão de controle externo do Poder Judiciário dificilmente poderia apontar para um melhor desenvolvimento econômico de um país. Ao menos seria difícil demonstrar essa relação causal. Ainda assim, são recorrentes as teses segundo as quais um Poder Judiciário mais eficiente gera crescimento econômico.

Há pouco material empírico para provar tal assertiva (THOME, 2000). Talvez estejamos nos focando na pergunta errada, que, inclusive, carrega desafios metodológicos grandes, vez que é impossível isolar a variável da reforma institucional, o que torna duvidosa a afirmação de que as mudanças - para melhor ou para pior - foram causadas pelas novas instituições (PRZEWORSKI, 2004).

Variáveis mais tangíveis poderiam ser identificadas, de modo a qualificar as discussões e conseguir resultados palpáveis. Buscaremos, no próximo tópico, lançar algumas ideias sobre contribuições que ainda não foram dadas pela literatura sobre Direito e Desenvolvimento ao Conselho Nacional de Justiça, em particular, e às reformas institucionais, em geral, para que possamos pensar em diagnósticos de realidade alternativos, que tomem por base avaliações empíricas consistentes.

\subsection{COMO A TeOria PODERIA CONTRIbUir PARA A REFleXÃo SObRe O CNJ?}


(...) what should be the response of global agencies and other actors involved in legal reform? At the risk of being simplistic, I would suggest looking back before heading South, and once heading South, looking South. (THOME, 2000, p.710)

Explicaremos, brevemente, como entendemos que podem ser as contribuições da literatura sobre Direito e Desenvolvimento para a reflexão sobre reformas institucionais no Brasil. Para tanto, levantaremos alguns temas que foram tocados ao longo deste artigo e que mereceriam aprofundamento da academia.

A composição do CNJ foi decidida em meio a grandes discussões. Os diferentes relatores da PEC 96/1992, bem como os setores chamados a se manifestar durante a tramitação, apresentaram propostas distintas sobre a composição ideal do Conselho (SADEK, 2001a). As discussões sobre o tema não podem mais se basear exclusivamente em opiniões sobre o que funcionaria melhor em um Conselho.

Com quase dez anos de funcionamento, é tempo para investigações empíricas sobre como vem se comportando o CNJ. Como decidem os conselheiros oriundos de diferentes carreiras? A origem de carreira é uma variável relevante para ser considerada? Como têm se mostrado as funções centrais - de Presidente e de Corregedor Nacional de Justiça - do CNJ? São infladas? Temos a hipótese de que as carreiras dos conselheiros importam, tanto por isso que houve intenso debate à época da escolha de sua composição. Uma composição mais equilibrada entre conselheiros juízes e não juízes poderia ser pensada, até porque as funções centrais já são exercidas por membros do Judiciário. A influência desses atores tem sido destacada na literatura (LASSANCE; SÁ E SILVA, 2013; CARVALHO; LEITÃO, 2013).

O temor de que as decisões de controle disciplinar poderiam adentrar em matéria jurisdicional é legítimo e tem sido levantado desde as primeiras discussões sobre um Conselho de Justiça. A Constituição Federal foi taxativa, impedindo tal hipótese. A normatização constitucional foi suficiente para garantir a independência da magistratura no exercício da sua função jurisdicional? Os magistrados têm recorrido de decisões do CNJ por esse motivo? É possível fazer algum diagnóstico sobre esse tema? Apesar dos magistrados muitas vezes recorrerem de sanções aplicadas, temos a hipótese de que a independência da magistratura tem sido respeitada. A ausência de questionamentos significativos por parte de suas associações de classe pode ser um indício da correção dessa leitura.

Neste ponto, poderíamos voltar novamente às declarações do atual Presidente do STF e do CNJ. Ele afirma que, por estar o Conselho previsto na Constituição e nas leis, não precisaria de nenhum apoio. Isso é realmente verdade? O CNJ é tão independente assim em sua atuação? Acreditamos, para ambas as questões, que não.

A transparência promovida pelo Conselho Nacional de Justiça, que se espalhou pelo Poder Judiciário, é notável. Podemos dizer que os mecanismos de transparência ativa têm mostrado resultado. Porém, é difícil negar que, para além da participação e apoio 
dos demais órgãos do Poder Judiciário, a participação da sociedade ou a porosidade a suas demandas têm se mostrado essenciais. Podemos dizer que o Conselho é poroso à participação da sociedade? Os cidadãos se sentem agasalhados pelo CNJ de forma a recorrer a ele em caso de (suspeita de) desvio funcional por parte de um magistrado?

Há pesquisas sobre a maior participação da sociedade em matéria normativa (ROSILHO, 2011), mas poderíamos nos questionar se ocorre algo semelhante em matéria de controle disciplinar. Iniciativas semelhantes ao Índice de Percepção das Leis no Brasil (IPCL) poderiam incluir o Conselho Nacional de Justiça, de forma a verificar como (ou se) a população percebe esse órgão. A hipótese é de que, ainda, o órgão não é bem conhecido pelos cidadãos brasileiros. Seria importante, por isso, que o CNJ se fizesse notar na sociedade como um todo, com maior divulgação de seu trabalho.

Outro tema, já mais estudado mas nunca esgotado por conta de sua relevância e dinamicidade, é a relação entre o Conselho Nacional de Justiça e o Supremo Tribunal Federal. Ele dialoga com as declarações do Ministro Joaquim Barbosa na medida em que a atuação do CNJ é tutelada pelo STF (CARVALHO, 2006, p. 109). O STF é o órgão de cúpula do Poder Judiciário, o qual o CNJ integra, e guarda da Constituição Federal. Essa construção teórico-normativa já oferece indícios para pensarmos em uma dependência do CNJ, sempre controlado pelo STF. O campo prático oferece ainda mais exemplos.

Em um já mencionado caso recente, podemos ter um diagnóstico ainda mais esclarecedor acerca da relação entre o STF e o CNJ. Trata-se da Medida Cautelar da ADI 4.638/DF, julgada pelo STF. O objeto da ação foi a Resolução 135/2011 do CNJ, que disciplina o procedimento administrativo disciplinar no âmbito do Conselho. Uma Associação de Magistrados (a Associação de Magistrados Brasileiros - AMB) questionou uma série de dispositivos normativos, alegando, de forma geral, desrespeito às garantias dos magistrados e à separação de Poderes.

O poder correcional do CNJ, ao final, foi respaldado pelo STF. Mas e se a Corte Suprema decidisse de forma distinta? E se, em decisão definitiva de mérito, a resposta for outra? Esse exemplo demonstra com clareza o fato de que a atuação do CNJ se apoiou e ainda se apoia no Supremo. O sinal foi positivo para o Conselho, a exemplo do que havia ocorrido na também já descrita ADI 3.367/DF. Porém, isso não enfraquece o argumento de que o funcionamento de nosso Conselho depende diretamente do órgão de cúpula do Poder Judiciário. Esse desenho institucional é adequado? Como ele responde aos casos disciplinares? O STF reverte as decisões do Conselho? São necessárias pesquisas empíricas para avaliar como tem se dado a tutela do STF às decisões disciplinares do CNJ, isto é, se são mantidas ou revistas. A hipótese é de que são, em sua maioria, mantidas. A revisão de um grande número de decisões do Conselho, inclusive, redundaria em um enfraquecimento do órgão.

\section{CONSIDERAÇÕES FINAIS}


Esse artigo buscou descrever como a literatura dominante sobre Direito e Desenvolvimento entende as reformas institucionais - com foco em um caso específico: o controle disciplinar da magistratura brasileira. A partir principalmente das ideias de Douglas North e Amartya Sen, traçamos um quadro descritivo desses autores identificados com o que se convencionou chamar de Rule of Law, que seriam características necessárias a uma sociedade que busca o desenvolvimento. Esse receituário, adotado hodiernamente por agências multilaterais, pauta-se na premissa de que reformas no Poder Judiciário que o tornem mais eficiente constituem incentivos ao crescimento econômico.

Algumas correntes críticas do Direito e Desenvolvimento discordam desses diagnósticos atrelados ao Rule of Law. Essas premissas passam a ser questionadas, sendo central a crítica de que não há elementos empíricos que demonstrem a relação entre eficiência do Poder Judiciário e desenvolvimento econômico de um país. São frequentemente mencionados os exemplos asiáticos que, com arranjos institucionais diferentes dos ocidentais, têm apresentado os maiores índices de crescimento econômico do mundo.

Diante desse quadro, procuramos testar os principais marcos teóricos identificados com o Rule of Law em face de um caso concreto brasileiro: o controle disciplinar no CNJ. A escolha metodológica recaiu sobre os três principais questionamentos sobre a criação do Conselho à época de sua tramitação. Da análise desses pontos, conclui-se que a abordagem teórica majoritária não consegue responder à maior parte das problemáticas surgidas em torno do CNJ, principalmente quando os questionamentos são sobre características peculiares da realidade brasileira, perceptíveis apenas por quem se debruce sobre esse país especificamente. Para matérias menos específicas, como a independência judicial, as teorias dominantes podem contribuir para relevantes reflexões sobre reformas institucionais.

Pelo caminho percorrido neste artigo, de descrição da inadequação de determinados postulados teóricos ao controle disciplinar exercido pelo Conselho Nacional de Justiça, podemos afirmar que é necessária a existência de pesquisas efetivamente aderentes à nossa realidade. São somente essas as capazes de refletir qualificadamente sobre as tantas questões que envolvem a Reforma do Judiciário. Há muitos temas latentes que demandam pesquisas qualificadas e específicas, conforme sugerimos. Entendemos que o estudo das instituições no campo de Direito e Desenvolvimento, que volta a ser relevante neste momento histórico, deve abarcar trabalhos acadêmicos questionadores, que não aceitem as premissas postas e procurem respostas satisfatórias e aderentes à realidade estudada, o que é feito por pesquisas que se preocupam em considerar as relevantes peculiaridades locais. Se o CNJ tem um papel já proeminente hoje, pode ter sua atuação ainda mais qualificada se a academia auxiliá-lo na

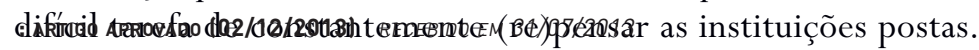




\section{NOTAS}

1 Trechos de palavras proferidas pelo Ministro Joaquim Barbosa em reunião com Associações da Magistratura ocorrida em 08 de abril de 2013, segundo o relato de Frederico Vasconcelos, articulista da Folha de S. Paulo, em seu blog: <http: / / blogdofred.blogfolha.uol.com.br/2013/04/ 08/dialogo-dificil-na-primeira-audiencia-concedida-porjoaquim-barbosa-as-associacoes-de-juizes/>. Acessado em: 17 abr. 2013.

2 Faz-se referência à Ação Direta de Inconstitucionalidade 3.367/2005, apreciada pelo Plenário do STF. Nessa ação, a Associação dos Magistrados Brasileiros (AMB) questionou, entre outros pontos menos relevantes para o objeto da pesquisa, o fato de a composição do Conselho não ser adstrita a magistrados e o fato de um controle sobre as atividades funcionais dos magistrados influenciar o exercício da jurisdição. Ela foi julgada totalmente improcedente pela maioria dos membros do Plenário.

3 Tratam-se de estudos que dialogam, embora apresentem consideráveis diferenças. Mariana Mota Prado (2011, p. 20) resume bem a questão: "in sum, Law \& Development scholars do not adopt one single concept of development, may disagree on the relationship between law and development, do not adopt one single methodology in their studies. (...) Without an answer to the three problems identified above, one is left without the answer to the quest for a solution to end world poverty. And until the answer is found, Law \& Development scholars will continue searching, being open to anything that may be potentially useful to ensure that every individual can choose to live the life that they have reason to value".

4 O conceito é assim definido: "institutions are the rules of the game in a society or, more formally, are the human devised constraints that shape human interaction. In consequence they structure incentives in human exchange, whether political, social or economic. Institutional change shapes the way societies evolve through time and hence is the key to understanding historical change" (NORTH, 1990, p. 3).

5 Esse termo é utilizado pelo fato de na agenda das agências internacionais serem utilizadas para avaliar a presença de Rule of Law "nada menos que 57 variáveis, que vão desde a confiança nas instituições do Estado, passando pelo Judiciário, sua independência e a sua forma de atuação, pela existência de altos níveis de criminalidade, pela efetividade dos contratos, garantia de direitos de propriedade - incluindo a propriedade intelectual -, existência de taxas de tráfico de pessoas e mesmo acesso à terra e água potável” (CUNHA, 2011, p. 238).

6 Itens reescritos com meras adaptações redacionais (CARVALHO, 2006).

7 Em recente pesquisa, Joaquim Falcão, Diego Werneck Arguelhes e Pablo de Camargo Cerdeira (2012) apontaram que 20 das 32 ações de controle concentrado de constitucionalidade propostas ao STF têm associações de classe da magistratura como requerentes. Os autores denominaram essa tática processual de judicialização permanente (texto disponível eletronicamente, sem página).

\section{REFERÊNCIAS BIBLIOGRÁFICAS}

CAROTHERS, Thomas. Promoting the Rule of Law Abroad: In Search of Knowledge. Washington, DC: Carnegie Endowment for International Peace, 2006.

CARVALHO, Ernani. O controle externo do Poder Judiciário: o Brasil e as experiências. Revista de Informação Legislativa, Brasília, v. 43, n.170, p. 99-109, 2006.

CARVALHO, Ernani; LEITÃO, Natalia. O poder dos juízes: Supremo Tribunal Federal e o desenho institucional do Conselho Nacional de Justiça. Revista de Sociologia e Política, Curitiba, n. 45, p. 13-27, março de 2013.

Disponível em: <http: / / www.scielo.br/scielo.php?script=sci_issuetoc\&pid=0104-

447820130001\&lng=en\&nrm=iso >. Acesso em: 10 out. 2013.

CUNHA, Luciana Gross. Rule of Law e desenvolvimento: os discursos sobre as reformas das instituições dos Sistemas de Justiça. In: VIEIRA, O. V.; DIMOULIS, D. (Org.). Estado de Direito e o Desafio do Desenvolvimento, v. 1. São Paulo: Saraiva, 2011, p. 233-246.

Relatório IPCL Brasil. Disponível em: <http://direitogv.fgv.br/sites/direitogv.fgv.br/files/ arquivos/anexos/ipcl_relatorio_4tri2012_1tri2013.pdf>. Acesso em: 19 jun. 2013. 
CUNHA, Luciana Gross; ALMEIDA, Frederico de. Justiça e desenvolvimento econômico na reforma do Judiciário brasileiro. In: SCHAPIRO, Mario; TRUBEK, David. Direito e Desenvolvimento: um diálogo entre os Brics. São Paulo: Saraiva, 2012.

FALCÃO, Joaquim; ARGUELHES, Diego Werneck; CERDEIRA, Pablo de Camargo. O diálogo entre o CNJ e o Supremo. Revista Interesse Nacional. São Paulo, edição 15, versão eletrônica sem página, janeiro de 2012.

Disponível em: <http://interessenacional.uol.com.br/author/jfalcao/>. Acesso em: 22 abr. 2013.

LASSANCE, Antonio; SÁ E SILVA, Fabio de. Agenda política e desafios institucionais: questões centrais para 2013, in IPEA, Boletim de Análise Político-Institucional 3, 2013.

MILHAUPT, Curtis J.; PISTOR, Katharina. Law and Capitalism: what corporate crisis reveal about legal systems and economic development around the world. Chicago and London: The University of Chicago Press, 2008.

NORTH, Douglas C. Institutions, Institutional change and economic performance. New York: Cambridge University Press, 1990.

OHNESORGE, John K. M. Developing Development Theory: Law \& Development Orthodoxies and Northeast Asian Experience. Legal Studies Research Paper Series. Paper n. 1024. University of Wisconsin Law School: July 2006. POSNER, Richard A. Creating a Legal Framework for Economic Development. The World Bank Research Observer, vol. 13, no. 1 (February 1998), pp. 1-11.

PRADO, Mariana Mota. What is Law and Development?. Revista Argentina de Teoria Jurídica, Belgrano, v. 11, n. 1, p. 1-20, Outubro de 2010 .

PRZEWORSKI, Adam. Institutions Matter? Disponível em: <http://onlinelibrary.wiley.com/doi/10.1111/j.14777053.2004.00134.x/pdf>. P. 527-540. Acessado em: 28 jun. 2013.

ROSILHO, A. J. O poder normativo do CNJ: um caminho para se pensar o experimentalismo institucional.

Revista Brasileira de Estudos Constitucionais, v. 1, p. 141-160, 2011.

SADEK, M. T. Controle Externo do Poder Judiciário. In: M. T. Sadek. (Org.). Reforma do Judiciário. São Paulo: Fundação Konrad Adenauer, 2001a, p. 91-180.

. Os juízes e a reforma do judiciário: textos para discussão. São Paulo: IDESP, $2001 \mathrm{~b}$.

SCHAPIRO, Mario; TRUBEK, David. Redescobrindo o Direito e Desenvolvimento: experimentalismo, pragmatismo democrático e diálogo horizontal. In: SCHAPIRO, Mario; TRUBEK, David. Direito e Desenvolvimento: um diálogo entre os Brics. São Paulo: Saraiva, 2012.

SEN, Amartya. Desenvolvimento Como Liberdade. São Paulo: Companhia das Letras, 2000a.

What is the role of legal and judicial reform in the development process? World Bank Legal

Conference, Washington, DC. Junho, $2000 \mathrm{~b}$.

TOMIO, Fabrício Ricardo de Limas; ROBL FILHO, Ilton Norberto. Accountability e independência judiciais: uma análise da competência do Conselho Nacional de Justiça. Revista de Sociologia e Política, Curitiba, n. 45, p. 29-46, março de 2013. Disponível em. <http://www.scielo.br/scielo.php?script=sci_issuetoc\&pid=0104-

447820130001\&lng=en\&nrm=iso $>$. Acesso em: 10 out. 2013.

THOME, Joseph R. Heading South but looking North: Globalization and Law Reform in Latin America. Wisconsin Law Review, n. 3, p. 691-712, Fall.

\section{Ivan Candido da Silva de Franco}

Rua Caracá, n. 250 Alto de Pinheiros - 05447-130

São Paulo - SP - Brasil

ivan.csfrancolagmail.com
Mestrando em Direito e Desenvolvimento na Escola de Direito de São Paulo da FundaÇÃo GETULIO VARGAS (DIREITO GV)
Rua Rocha, n. 233, $11^{\circ}$ andar São Paulo - SP - Brasil

luciana.cunhalafgr.br

\section{Luciana Gross Cunha}

Professora da Escola de Direito de São Paulo da Fundação Getulio Vargas (DIREITO GV) 
